\title{
Caries, Oral Health Knowledge, Behavior, and Barriers to Care Among a Group of Urban Poor in the Philippines: An Overview
}

\author{
${ }^{1}$ Vincent Torresyap, ${ }^{2}$ Alyssa Hayes, ${ }^{3}$ Jay Hoover, ${ }^{4}$ Chandima Karunanayake
}

\begin{abstract}
Purpose: To provide an overview of the caries status and needs, knowledge, behavior and barriers to oral health in a group of adults from a poor urban community in the Philippines.

Materials and methods: 401 subjects aged 16 to 85 years (Mean \pm SD: $41.4 \pm 15.2$ ) were assessed for caries status and needs, oral mucosal lesions and fluorosis using the $1997 \mathrm{WHO}$ format and interviewed using a structured questionnaire. The examinations were conducted in natural light with a mouth mirror and an explorer with the subject seated in a regular chair. One-way ANOVA was used to compare the means and Chi-square and Fisher's exact test was used to compare the proportions. The significance level was set at $\alpha=0.05$.
\end{abstract}

Results: The mean DMFT for the whole sample was 15.59 . Older adults had more missing teeth compared to their younger counterparts ( $0.73 \mathrm{MT}$ for $\leq 20$ years; $22.13 \mathrm{MT}$ for $\geq 71$ years) while the number of mean untreated decay was higher among the younger age cohorts with those aged 21 to 30 years of age experiencing the most untreated decay (DT of 9.37). The need for extractions increased with age (1.70; SD 1.92 teeth in 6170 year-olds) and the need for multi-surface fillings (6.59, SD 2.86) was greatest among young adults. In general, the oral health knowledge and awareness of the importance of good oral hygiene was high, however, only $33 \%$ reported seeing a dentist in the previous 2 years. Over $82 \%$ reported their perceived oral health as fair to poor, suggesting that this urban, poor population is aware of their needs, but face financial barriers to acting on this perceived need.

Conclusion: A large percentage of the present sample of Filipino adults had significant unmet caries needs and adequate finances were the main barrier to seeking care at a dental office.

Keywords: Philippines, Caries, Poor, Knowledge, Adults.

How to cite this article: Torresyap V, Hayes A, Hoover J, Karunanayake C. Caries, Oral Health Knowledge, Behavior, and Barriers to Care Among a Group of Urban Poor in the Philippines: An Overview. Int J Prosthodont Restor Dent 2014;4(2):39-45.

\footnotetext{
${ }^{1,2}$ Assistant Professor, ${ }^{3}$ Professor, ${ }^{4}$ Biostatistician

${ }^{1-3}$ College of Dentistry, University of Saskatchewan, Saskatchewan, Canada

${ }^{4}$ Canadian Centre for Health and Safety in Agriculture University of Saskatchewan, Saskatchewan, Canada
}

Corresponding Author: Vincent Torresyap, Assistant Professor College of Dentistry, University of Saskatchewan, Saskatchewan Canada, Phone: 3069665087, e-mail: vincent.torresyap@usask.ca
Source of support: University of Saskatchewan

Conflict of interest: None

\section{INTRODUCTION}

Although the prevalence of dental caries is on the decline in Europe and North America, it is still considered to be moderate to high in many regions of the developing world and linked to selected systemic diseases, especially in underprivileged population groups. ${ }^{1-5}$

Regrettably, oral health is usually not considered a priority issue by the public health sector in developing countries, particularly among disadvantaged groups such as the urban poor. When one combines factors such as economic barriers, low utilization of existing oral health services and a scarcity of preventive oral health programs, preventable oral conditions occur, such as caries and periodontal disease, resulting in orofacial discomfort or pain and tooth loss. ${ }^{6}$

Large segments of the population in developing nations consist of rural dwellers and the urban poor. It is well established that there are discrepancies in health including oral health between the urban rich and the urban poor especially in these countries. ${ }^{7}$ According to a report published by the World Bank, 'the urban poor are particularly vulnerable in times of crisis due to their heavy reliance on a cash economy, job losses and wage reductions in urban-based industries, and no agricultural production to fall back on. ${ }^{8}$ Although the definition of urban poverty is not well-defined, the National Statistical Coordination Board of the Republic of the Philippines, describes the Urban poor as an individual residing in an urban area whose income falls below the official poverty threshold. ${ }^{9}$ In 2009, the annual per capita poverty threshold in the Philippines was PhP 16841, about US\$ 385 per year. ${ }^{10}$ IBON Foundation, Inc., an independent development institution established in 1978, reported in a recent survey, that approximately just over $68 \%$ of the population in the Philippines considered themselves as poor. ${ }^{11}$

The prevalence of oral diseases continues to be a public health issue in the country. According to data published by the Department of Health, Republic of the Philippines, it is estimated that more than $75 \%$ of the adult population have some form of periodontal disease, ${ }^{12}$ while $82 \%$ of 12 -year-old 
had caries (mean DMFT 2.9). ${ }^{13}$ Besides data fro m a few national surveys, there is a dearth of published information concerning the oral health status and needs, knowledge and attitudes of adult Filipinos especially in those considered the Urban poor or poor. Knowledge, attitudes and awareness are important prerequisites to effect a change in behavior, including behavior associated with health and disease prevention. ${ }^{14}$ In addition, it has been established that a lack of awareness of the importance of deciduous teeth can adversely affect the oral health of children especially in their preschool years. $^{15,16}$

The aim of the present study was to determine caries status and treatment needs, oral health knowledge, attitudes, and barriers to care in a group of adult Filipinos residing in a poor urban community in the City of San Jose, located in the province of Batangas, Philippines.

\section{MATERIALS AND METHODS}

San Jose is situated in the province of Batangas, Philippines about $85 \mathrm{~km}$ from the capital city of Manila. According to the 2010 census, San Jose had a population of 68,517 people living in approximately 10,000 households. ${ }^{17}$

The subjects in the present study were selected using a convenience sample of adults recruited from Barangay Banay-Banay, a poor district in the city and one of thirty three urbanized Barangays comprising the City of San Jose. A Barangay refers to an administrative unit, district, village, ward, suburb or inner city neighborhood. Banay-Banay is approximately $4 \mathrm{~km}$ from the city proper of San Jose. The reasons for obtaining a convenience sample were mainly due to a combination of budgetary and time constraints as well as the need to establish some form of baseline data in this population group. Furthermore, it was not possible to obtain a recent census list or valid population registers. The study was conducted in full accordance with ethical principles and with the approval of the behavioral Research Ethics Board, University of Saskatchewan, Canada.

Sample size calculations indicated that a minimum of 288 participants were needed to be assessed in order to detect a 6 to $10 \%$ increase in the prevalence of dental caries and periodontal diseases compared to the general population at $\alpha=0.05$ (Type I error) with power of $80 \% .^{18,19}$ To reduce the margin of error further, it was decided to obtain a sample size of approximately 400 adults aged 16 years and older who were recruited by going door to door and requesting participation till the target size was reached.

Oral examinations were conducted by a calibrated dentist, aided by a recording assistant in a rented facility, in natural light and using a dental mirror and an explorer with the subjects seated in a regular chair. A battery operated head lamp was used as an added source of illumination. Intra-rater reliability was assessed with the Intra-Class Correlation Coefficient (ICC) prior to the survey. Using the sample size determination approach described by Shrout and Fleiss, ${ }^{20}$ eight adult subjects were selected at random to achieve an $80 \%$ power with agreement of 0.8 intraexaminer variability and two repeated measures. The result of the intraclass cor-relation was 0.925 for the examiner. Decayed, missing, and filled components were recorded in all dentate individuals along with dentition status and treatment needs, fluorosis and oral mucosal lesions using the $\mathrm{WHO}$ oral health assessment form. ${ }^{21}$

Additionally, prosthodontic occlusal relationships, periodontal status and treatment needs were assessed. The results of the analyses of this data have been reported recently. ${ }^{22}$ All subjects were also requested to complete a questionnaire covering the following areas: oral health knowledge and practices, perceived oral health status, smoking habits and concerns regarding barriers to oral care. It was assumed that a majority of the sample population would most likely have a limited knowledge of spoken and written English posing a problem responding to a standard English language questionnaire format. Therefore the questionnaires and the consent forms were translated from English to Tagalog, the indigenous language of the Philippines. Further, the interview instrument was designed to facilitate a face to face approach and a member of the study team fluent in English and Tagalog was available at all times to assist with any questions the participants may have had. A signed consent was obtained prior to the examination and a copy provided to each subject.

The statistical analysis was carried out using SPSS software (version 21.0). Data was presented using frequencies, percentages, means, standard deviations (SD) and 95\% confidence intervals (CI), where applicable. Dental caries prevalence and DMFT were presented stratifying by demographics age, gender and education level.

\section{RESULTS}

A total of 401 subjects aged 16 to 85 years (Mean \pm SD: $41.4 \pm 15.2)$ were included in the study. There were no significant findings in terms of oral mucosal lesions and dental fluorosis and hence the data was not tabulaed. Thirty one subjects $(7.7 \%)$ were totally edentulous while $57(14.2 \%)$ had all their natural teeth (third molars were excluded). A total of 7998 teeth was examined.

Table 1 shows that of those surveyed, over $66 \%$ were between the ages of 21 and 50 years, with the majority being female (females $84 \%$; males $16 \%$ ). In terms of education, over $90 \%$ of participants reported their highest level of 
educational attainment as less than or equal to 4 th year high school. (In the Philippines, the highest achievement below college is 4 th year high school or grade 10 equivalent).

Table 2 illustrates the role of age in caries experience. The mean DMFT for the whole sample was 15.59 and the mean DT was 7.54. As age increases, so does the mean DMFT score, with those over 71 years of age, having a mean DMFT of over 25 teeth affected by caries compared to almost 10 teeth being affected in those under 20 years of age. Expectedly older subjects had more missing teeth compared to their younger counterparts $(0.73 \mathrm{MT}$ for $\leq 20$ years; $22.13 \mathrm{MT}$ for $\geq 71$ years). While the number of mean untreated decay was higher among the younger age cohorts with those aged 21 to 30 years of age experiencing the most untreated decay (DT of 9.37). Differences are also seen between males and females, with males having a higher mean DMFT (15.81) and having more missing teeth (8.86), while females experience more decayed teeth (7.65). Those with less than high school education have over 3 more teeth affected by decay compared to those with greater than high school ( $\leq$ HS $15.89 v s>$ HS 12.61).

Table 1: Demographics among study population $(n=401)$

\begin{tabular}{lll}
\hline & Frequency & Percentage (\%) \\
\hline $\begin{array}{l}\text { Age groups, in years } \\
\text { (Mean } \pm \text { SD: 41.4 } \pm \text { 15.2) }\end{array}$ & & \\
$\leq 20$ & 22 & 5.5 \\
$21-30$ & 89 & 22.2 \\
$31-40$ & 105 & 26.2 \\
$41-50$ & 73 & 18.2 \\
$51-60$ & 57 & 14.2 \\
$61-70$ & 43 & 10.7 \\
$\geq 71$ & 12 & 3.0 \\
Sex & & \\
Male & 64 & 16.0 \\
Female & 337 & 84.0 \\
Educational background & & \\
$>$ High school (HS) & 36 & 9.0 \\
$\leq$ High school (HS) & 365 & 91.0 \\
\hline
\end{tabular}

Table 3 highlights the treatment needs attributed to the level of decay in Table 2. The need for extractions increased with age (mean $=1.70 ; \mathrm{SD}=1.92$ teeth in 61-70 year-olds) while the need for multi-surface fillings (mean $=6.59$; SD $=2.86$ ) was greatest among young adults.

Tables 4 and 5 show that almost all participants recognized the importance of teeth for daily living (97\%). In general oral health awareness was high with 94\% reporting to know the importance of brushing at night; $67 \%$ understanding the importance of baby teeth and $84 \%$ knowing that fluoride was beneficial to their oral health. Conversely, only $33 \%$ indicated seeing a dentist in the previous 2 years, yet almost $88 \%$ reported the likelihood of seeing a dentist for a check-up in the future.

Table 6 highlights the use of removable dental prostheses. The majority of those surveyed indicated not wearing either full or partial removable dentures $(91 \%$ and $81 \%$, respectively). Table 7 deals specifically with tobacco use, showing that over $65 \%$ of those surveyed reported never smoking and that of those who do smoke, almost $65 \%$ have considered quitting. Interestingly, almost all (99.5\%) participants who were surveyed mentioned that they did not chew betel leaf or quid. Table 8 shows that of those surveyed, over $90 \%$ reported a lack of money as a barrier to oral care while only $2.5 \%$ reported fear of pain as a deterrent. Over $82 \%$ stated their perceived oral health as fair to poor, suggesting that this Urban poor population was aware of their needs but face financial barriers to acting on this perceived need.

\section{DISCUSSION}

To the best of our knowledge, this is the first time that the prevalence of dental caries and treatment needs, oral health knowledge, attitudes and barriers to oral care have been documented in a group of adults living in a relatively poor district in the Philippines.

Table 2: Dental caries prevalence and DMFT (Decayed, Missing and Filled)* according to demographics

\begin{tabular}{|c|c|c|c|c|c|c|c|}
\hline \multirow[t]{2}{*}{ Characteristics } & \multirow[t]{2}{*}{$N$} & \multicolumn{2}{|c|}{ Decayed } & \multicolumn{2}{|c|}{ Missing } & \multicolumn{2}{|c|}{ DMFT } \\
\hline & & Mean & $95 \% \mathrm{Cl}$ & Mean & $95 \% \mathrm{Cl}$ & Mean & $95 \% \mathrm{Cl}$ \\
\hline All & 401 & 7.54 & $7.08-8.00$ & 8.05 & $7.19-8.91$ & 15.59 & $14.86-16.32$ \\
\hline Age $\leq 20$ & 22 & 8.91 & $7.25-10.56$ & 0.73 & $0.30-1.16$ & 9.64 & $8.04-11.23$ \\
\hline Age 21-30 & 89 & 9.37 & $8.47-10.26$ & 2.17 & $1.60-2.73$ & 11.54 & $10.50-12.58$ \\
\hline Age $31-40$ & 105 & 8.85 & $7.99-9.70$ & 4.10 & $3.32-4.89$ & 12.95 & $11.77-14.13$ \\
\hline Age 41-50 & 73 & 7.11 & $6.11-8.11$ & 9.61 & $7.84-11.39$ & 16.73 & $15.11-18.33$ \\
\hline Age 51-60 & 57 & 5.07 & $4.01-6.13$ & 14.56 & $12.23-16.89$ & 19.63 & $17.81-21.45$ \\
\hline Age 61-70 & 43 & 4.93 & $3.51-6.35$ & 18.42 & $15.59-21.24$ & 23.35 & $21.49-25.21$ \\
\hline Age $\geq 71$ & 12 & 3.67 & $1.13-6.20$ & 22.17 & $17.88-26.45$ & 25.83 & $23.01-28.66$ \\
\hline Male & 64 & 6.95 & $5.83-8.08$ & 8.86 & $6.60-11.12$ & 15.81 & $13.83-17.80$ \\
\hline Female & 337 & 7.65 & $7.14-8.15$ & 7.90 & $6.97-8.84$ & 15.55 & $14.76-16.34$ \\
\hline >High school (HS) & 36 & 7.39 & $6.24-8.54$ & 5.22 & $3.22-7.22$ & 12.61 & $10.82-14.40$ \\
\hline sHigh school (HS) & 365 & 7.55 & $7.06-8.05$ & 8.33 & $7.41-9.26$ & 15.89 & $15.11-16.67$ \\
\hline
\end{tabular}

*There were no filled teeth without decay. Therefore, DMFT was based on summation of decayed and missing teeth 
Table 3: Comparison of age of study population with treatment needs

\begin{tabular}{llll}
\hline Age (in years) & $N$ & $\begin{array}{l}\text { Two or more } \\
\text { surface filling } \\
\text { Mean }(S D)\end{array}$ & $\begin{array}{l}\text { Extraction } \\
\text { Mean }(S D)\end{array}$ \\
\hline$\leq 20$ & 22 & $6.59(2.86)$ & $0.91(0.97)$ \\
$21-30$ & 89 & $5.81(3.20)$ & $1.38(1.69)$ \\
$31-40$ & 105 & $4.66(3.02)$ & $1.26(1.65)$ \\
$41-50$ & 73 & $3.57(2.90)$ & $1.45(1.86)$ \\
$51-60$ & 57 & $2.28(2.18)$ & $1.05(1.47)$ \\
$61-70$ & 43 & $1.14(1.85)$ & $1.70(1.92)$ \\
$\geq 71$ & 12 & $1.50(3.0)$ & $1.00(1.28)$ \\
\hline Total & 401 & $4.01(3.25)$ & $1.31(1.67)$ \\
\hline
\end{tabular}

The present sample comprised of predominantly females, which was expected considering the fact that the study was conducted during the week days when mostly men would be working outside of the home. Likewise, a relatively higher number of female respondents have been reported in other descriptive studies of a similar nature. ${ }^{23-25}$ Not surprisingly, considering the sample was obtained from a relatively poor district, the majority of those surveyed reported having less than a high school education (91\%). In terms of decay experience, this study found that all participants experienced decay $(100 \%)$ with an average of over 15 teeth being affected (mean DMFT $=15.59$ ), levels which have not changed substantially over several decades in the Philippines. ${ }^{26}$ Further to this were the findings that both, males and those with lower educations had higher mean DMFT scores (males, mean $\mathrm{DMFT}=15.81 ; \leq \mathrm{HS}$ mean DMFT $=15.89$ compared to their female and probably better educated counterparts. Conversely the majority of participants (78\%) reported to have never smoked or had quit smoking. Among current smokers almost $65 \%$ stated to have considered quitting. These findings are consistent with the 2009 Global Adult Tobacco Survey (GATS) for the country which found that approximately $24 \%$ of the Filipino population smoked with 5 times more males reporting being smokers compared to females $(47.7 \%$ males vs $9 \%$ females). Furthermore, the GATS (2009) indicated that over $60 \%$ of current smokers were interested in quitting. ${ }^{27}$

Almost all participants (99\%) reported not chewing betel leaf (Piper betle) or quid (a mix of the leaf and areca nut), a practice associated with oral submucous fibrosis and oral carcinoma, and still endemic in many parts of South and South East Asia and Melanesia. ${ }^{28}$

Concerning reported barriers to oral healthcare, lack of money was the most common response $(91.8 \%)$, followed by fear of pain (2.5\%) both of which are consistent with the literature. ${ }^{25,29}$ Interestingly, though when participants were questioned about their oral health knowledge the majority declared that they understood the importance of teeth for activities required for daily living (i.e. eating, speaking and esthetics). Further to this, respondents demonstrated a basic understanding of oral health practices; $93 \%$ reported brushing after meals, $77 \%$ recognized that bleeding gums were not healthy; $82 \%$ said tooth brushing was to remove bacteria, and almost all mentioned brushing at least once per day $(99 \%)$. While it is encouraging that in the select sample of Urban poor, oral health knowledge is present, this knowledge may not translate to utilization of dental services with only $33 \%$ indicating seeing a dentist in the previous 2 years. However, the understanding that dental care is accessed largely via out of pocket payments in the Philippines demonstrates a need for affordable, accessible dental programs for this population (i.e. Urban poor).

Despite providing some insight into the caries experience of a selected group of the Urban poor in the Philippines, this study has some limitations. The use of a convenience sample limits the generalizability of the data. Also, as with all self-reported data (oral health knowledge) bias is possible. Studies using randomized sampling in other locales should be undertaken to determine if similar needs exist in adults in the Philippines with regards to dental caries.

Nevertheless, the data presented here do begin to fill a key knowledge gap concerning the oral health of poor, Urban Filipino adults. Based on the findings of the present study and considering the economic and political stability of the country, it is unlikely that traditional approaches to prevent and treat common oral diseases such as caries in the context of limited resources will succeed in addressing the unmet dental needs of the population. Instead, it may be prudent for local government and dental nongovernmental organizations to find means of integrating oral disease preventive programs into the broader national health plans. Further, to consider applying and integrating innovative and inexpensive, feasible and sustainable treatment modalities, such as the WHO's basic package of oral care which includes oral urgent treatment (OUT), affordable fluoride toothpastes (AFT) and atraumatic restorative treatment (ART) ${ }^{30,31}$ Oral health initiatives in the Philippines should also include a systematic risk factor review similar to those being conducted by WHO Global Oral Health Program as part of the planning process. ${ }^{32}$

\section{CONCLUSION}

The results of this pilot study indicate that the majority of Filipino adults living in a poorer section of the city of San Jose, Batangas has unmet caries needs that require prompt attention. Although oral health knowledge and awareness of the importance of good oral hygiene was high, financial reasons were the main barrier to oral care. Cost effective and innovative means of managing the high prevalence of unmet dental needs in this often marginalized segment of 
Table 4: Knowledge and awareness of dental and general health among the study population $(n=401)$

\begin{tabular}{|c|c|c|}
\hline & Frequency & Percentage (\%) \\
\hline \multicolumn{3}{|c|}{ Why are teeth important to you? } \\
\hline To eat properly & 84 & 20.9 \\
\hline To speak properly & 2 & 0.5 \\
\hline To have a pleasant smile & 2 & 0.5 \\
\hline All of the above & 305 & 76.1 \\
\hline Do not know & 8 & 2.0 \\
\hline \multicolumn{3}{|c|}{ Should you clean your teeth before or after meals? } \\
\hline Before & 17 & 4.2 \\
\hline After & 372 & 92.8 \\
\hline Do not know & 12 & 3.0 \\
\hline \multicolumn{3}{|c|}{ Should you brush your teeth before going to bed at night? } \\
\hline Yes & 377 & 94.0 \\
\hline No & 17 & 4.2 \\
\hline Do not know & 7 & 1.8 \\
\hline \multicolumn{3}{|c|}{ How many baby teeth does a 3-year old have? } \\
\hline 10 & 364 & 90.8 \\
\hline 20 & 4 & 1.0 \\
\hline 25 & 1 & 0.2 \\
\hline 32 & 32 & 8.0 \\
\hline \multicolumn{3}{|l|}{ Do not know } \\
\hline \multicolumn{3}{|c|}{ Are baby teeth as important as adult teeth? } \\
\hline Yes & 269 & 67.1 \\
\hline No & 115 & 28.7 \\
\hline Do not know & 17 & 4.2 \\
\hline \multicolumn{3}{|c|}{ Which of the following most harmful to your teeth? } \\
\hline Potato & 1 & 0.2 \\
\hline Sweets & 385 & 96.0 \\
\hline Rice & 4 & 1.0 \\
\hline Bread & 0 & 0.0 \\
\hline Do not know & 11 & 2.7 \\
\hline \multicolumn{3}{|c|}{ Is it 'OK' if your gums bleed when you clean your teeth? } \\
\hline Yes & 79 & 19.7 \\
\hline No & 308 & 76.8 \\
\hline Do not know & 14 & 3.5 \\
\hline \multicolumn{3}{|c|}{ Have you heard of dental plaque? } \\
\hline Yes & 48 & 12.0 \\
\hline No & 160 & 39.9 \\
\hline Do not know & 193 & 47.1 \\
\hline \multicolumn{3}{|c|}{ Have you ever heard of fluoride? } \\
\hline Yes & 325 & 81.0 \\
\hline No & 48 & 12.0 \\
\hline Do not know & 28 & 7.0 \\
\hline \multicolumn{3}{|c|}{ What does fluoride do for your teeth? } \\
\hline Makes them strong & 333 & 83.0 \\
\hline Makes them loose & 3 & 0.7 \\
\hline Makes the gums bleed & 3 & 0.7 \\
\hline Do not know & 62 & 15.5 \\
\hline \multicolumn{3}{|c|}{ What do you think is the main reason for brushing your teeth? } \\
\hline To make them whiter & 45 & 11.2 \\
\hline To freshen breath & 18 & 4.5 \\
\hline To remove bacteria & 329 & 82.1 \\
\hline Do not know & 9 & 2.2 \\
\hline
\end{tabular}


Table 5: Behavior of dental and general health among the study population

\begin{tabular}{|c|c|c|}
\hline & Frequency & Percentage (\%) \\
\hline \multicolumn{3}{|c|}{ Do you have a toothbrush of your own $(n=401) ?$} \\
\hline Yes & 391 & 97.5 \\
\hline No & 10 & 2.5 \\
\hline \multicolumn{3}{|c|}{ How often do you brush your teeth $(n=391) ?$} \\
\hline One or more times per day & 389 & 99.5 \\
\hline Less than once a day & 2 & 0.5 \\
\hline \multicolumn{3}{|c|}{ Has a dentist ever shown you how to brush $(n=401) ?$} \\
\hline Yes & 230 & 57.4 \\
\hline No & 171 & 42.6 \\
\hline \multicolumn{3}{|c|}{ Do you think you will need false teeth when you grow older $(n=401) ?$} \\
\hline Yes & 234 & 58.4 \\
\hline No & 127 & 31.7 \\
\hline Do not know & 40 & 9.9 \\
\hline \multicolumn{3}{|c|}{ Have you been to a dentist in the last 2 years $(n=401) ?$} \\
\hline Yes & 132 & 32.9 \\
\hline No & 246 & 61.3 \\
\hline Do not know & 23 & 5.7 \\
\hline \multicolumn{3}{|c|}{ Will you likely see to a dentist regularly for a checkup in the future $(n=401) ?$} \\
\hline Yes & 352 & 87.8 \\
\hline No & 34 & 8.5 \\
\hline Do not know & 15 & 3.7 \\
\hline \multicolumn{3}{|c|}{ Are you afraid of seeing a dentist $(n=401) ?$} \\
\hline Yes & 13 & 3.3 \\
\hline No & 385 & 96.0 \\
\hline Do not know & 3 & 0.7 \\
\hline
\end{tabular}

Table 6: Removable prostheses among the study population

\begin{tabular}{lll}
\hline & Frequency & Percentage $(\%)$ \\
\hline Do you currently wear a full denture plate $(n=383)$ ? & 36 & 9.4 \\
Yes & 347 & 90.6 \\
No & & 19.2 \\
Do you currently wear a removable partial denture plate $(n=365) ?$ & 70 & 80.8 \\
Yes & 295 & \\
No
\end{tabular}

Table 7: Tobacco habits among the study population

\begin{tabular}{|c|c|c|}
\hline & Frequency & Percentage (\%) \\
\hline \multicolumn{3}{|c|}{ Smoking status $(n=353)$} \\
\hline Current smoker & 79 & 22.4 \\
\hline Ex-smoker & 37 & 10.5 \\
\hline Never smoked & 237 & 67.1 \\
\hline \multicolumn{3}{|c|}{ Do you believe smoking is harmful to your health $(n=141) ?$} \\
\hline Yes & 131 & 92.9 \\
\hline No & 8 & 5.7 \\
\hline Do not know & 2 & 1.4 \\
\hline \multicolumn{3}{|c|}{ Do you believe inhaling other people's smoke is harmful to your health $(n=140) ?$} \\
\hline Yes & 133 & 95.0 \\
\hline No & 4 & 2.9 \\
\hline Do not know & 3 & 2.1 \\
\hline \multicolumn{3}{|c|}{ If you do smoke, have you ever thought of quitting $(n=79) ?$} \\
\hline Yes & 51 & 64.6 \\
\hline No & 28 & 35.4 \\
\hline \multicolumn{3}{|c|}{ Do you chew betel leaf/quid $(n=401) ?$} \\
\hline Yes & 2 & 0.5 \\
\hline No & 399 & 99.5 \\
\hline
\end{tabular}


Table 8: Barriers to oral care and perceived oral health status among the study population $(n=401)$

\begin{tabular}{lll}
\hline & Frequency & Percentage (\%) \\
\hline Barriers to oral care $(n=401)$ & & \\
Lack of money & 368 & 91.8 \\
Lack of dental insurance & 4 & 1.0 \\
Fear of pain & 10 & 2.5 \\
Work schedule & 8 & 2.0 \\
Lack of transportation & 6 & 1.5 \\
Perceived oral health status & & \\
Condition of your teeth and gums & & \\
$\quad$ Good to Excellent & 58 & 14.5 \\
$\quad$ Fair to Poor & 329 & 82.1 \\
$\quad$ Not applicable & 14 & 3.4 \\
\hline
\end{tabular}

the population should be a priority of public health officials and dental NGO's in the Philippines.

\section{ACKNOWLEDGMENT}

The authors wish to thank the organizers and participants involved in the study which was partly supported by the endowment fund, College of Dentistry, University of Saskatchewan, Canada.

\section{REFERENCES}

1. WHO. World Oral Health Report 2003. Continuous improvement in oral health in the 21st century-the approach of the WHO oral health program. Petersen PK. Oral health program. Non communicable disease prevention and health promotion. Available from: Geneva, Switzerland.

2. Okunseri C, Bajorunaite R, Abena A, Self K, Iacopino AM, Flores G. Racial/ethnic disparities in acceptance of medicaid patients in dental practices. J Public Health Dent 2008 Summer; 68(3):149-153.

3. Lawrence HP, Leake JL. The US Surgeon General's report on oral health in America: a Canadian perspective. J Can Dent Assoc 2001 Nov;67(10):587.

4. Downer MC. Caries prevalence in the United Kingdom. Int Dent J 1994 Aug;44(4 Suppl 1):365-370.

5. Von der Fehr FR. Caries prevalence in the Nordic countries. Int Dent J 1994 Aug;44(4 Suppl 1):371-378.

6. Uetani M, Jimba M, Kaku T, Ota K, Wakai S. Oral health status of vulnerable groups in a village of the Central Highlands, Southern Vietnam. Int J Dent Hyg 2006 May;4(2):72-76.

7. Singh A, Purohit BM. Dental Public Health: a mistaken identity. Adv Life Sci Appl 2012;1(3):58-61.

8. Baker JL. Impacts of financial, food, and fuel crisis on the urban poor. Directions in urban development. Washington, DC: Urban Development Unit, World Bank; 2008 Dec [cited 2008 Dec]. p. 1-4. Available at: http://siteresources.worldbank. org/inturbandevelopment/Resources/336387-1226422021646/ directions_2.pdf?resourceurlname=directions_2.pdf.

9. Castro LV. Users' forum on the 2006 poverty statistics for the basic sectors and 2006 child development index. Republic of the Philippines: National Statistical Coordination Board; 2009 June [cited 2009 June]. Available at: http://www.nscb.gov.ph/ poverty/default.asp.
10. Virola RA. 2009 Official Poverty Statistics. Republic of the Philippines: National Statistical Coordination Board; 2011 June [cited 2011 June]. Available at: http://www.nscb.gov.ph/ poverty/2009/Presentation_RAVirola.pdf.

11. IBON Survey: Most Filipinos say corruption, poverty did not improve; self-rated poverty also increased to $67 \%$. Available at: http://www.ibon.org/ibon_surveys.php.

12. Republic of the Philippines: Department of Health. Available at: www.doh.gov.ph/node/1066.html.

13. Benzian H, Monse B, Heinrich-Weltzien R, Hobdell M, Mulder J, van Palenstein Helderman W. Untreated severe dental decay: a neglected determinant of low body mass index in 12-year-old Filipino children. BMC Public Health 2011 Jul 13;11:558.

14. Green W, Kreuter M. Health promotion planning: an educational and ecological approach. 3rd ed. Mountain View, CA: Mayfield Pub Co; 1999.

15. Wong D, Perez-Spiess S, Julliard K. Attitudes of Chinese parents toward the oral health of their children with caries: a qualitative study. Pediatr Dent 2005 Nov-Dec;27(6):505-512.

16. Chhabra N, Chhabra A. Parental knowledge, attitudes and cultural beliefs regarding oral health and dental care of preschool children in an Indian population: a qualitative study. Eur Arch Paediatr Dent 2012 Apr;13(2):76-82.

17. 'Total Population by Province, City, Municipality and Barangay: as of May 1, 2010'. 2010 Census of Population and Housing. National Statistics Office. Retrieved 11 November 2013.

18. MachinD, CampbellM,FayersP,PinolA.Samplesizetables forclinical studies. 2nd ed. Oxford: Blackwell Science Ltd; 1997. p. 21-22.

19. Altman DG, Machin D, Bryant TN, Gardner MJ. Statistics with confidence. 2nd ed. London, UK: BMJ Books; 2000. p. 46-47.

20. Shrout PE, Fleiss JL. Intraclass correlations: uses in assessing rater reliability. Psychol Bulletin 1979;86(2):420-428.

21. World Health Organization. Oral Health Surveys: Basic methods. 4th ed. Geneva: World Health Organization; 1997.

22. Torresyap V, Hoover J, Torresyap M, Karunanayake C. Prosthodontic and periodontal status and needs in a selected population of urban poor in the Philippines. Int J Prosthodont Oper Dent 2013;3(4):136-142.

23. Brothwell DJ, Jay M, Schönwetter DJ. Dental service utilization among independently dwelling older adults in Manitoba, Canada. J Can Dent Assoc 2008 Mar;74(2):161-161f.

24. Kikwilu EM, Masalu JR, Kahabuka FK, Senkoro AR. Prevalence of oral pain and barriers to use of emergency oral care facilities among adult Tanzanians. BMC Oral Health 2008 Sep 29;8:28.

25. Ajayi DM, Arigbede AO. Barriers to oral health care utilization in Ibadan, South WestNigeria. AfrHealthSci2012 Dec; 12(4):507-513.

26. Republic of the Philippines: Department of Health. Available at: http://www.doh.gov.ph/node/1066.html.

27. Philippines Global Adult tobacco Survey (GATS) Report. Country Report: Phillipines 2009. Geneva: World Health Organization; 2010. Available at: http://www.who.int/tobacco/ surveillance/2009_gats_report_philippines.pdf?ua=1.

28. Gupta PC, Warnakulasuriya S. Global epidemiology of areca nut usage. Addict Biol 2002 Jan;7(1):77-83.

29. Freeman R. Barriers to accessing dental care: patient factors. Br Dent J 1999 Aug 14;187(3):141-144.

30. Helderman WV, Benzian H. Implementation of a basic package of oral care: towards a reorientation of dental NGOs and their volunteers. Int Dent J 2006 Feb;56(1):44-48.

31. Janet Han S, Quinonez CR. Dental volunteerism: is the current model working? J Can Dent Assoc 2013;79:d69.

32. Petersen PE. Sociobehavioural risk factors in dental caries - an international perspective. Comm Dent Oral Epidemiol 2005;33:274-279. 